\title{
Persistence with Denosumab in Women at High Risk of Fracture in Bulgaria
}

\author{
Simeon Monov $\cdot$ Rodina Nestorova $\cdot$ Margarita Velkova \\ Mihail Boyanov $\cdot$ Silvia Jeleva $\cdot$ Renata Petkova $\cdot$ Tzvetanka Petranova
}

Received: October 9, 2020 / Accepted: November 24, 2020 / Published online: February 8, 2021

(C) The Author(s) 2021

\section{ABSTRACT}

Introduction: Post-menopausal women with osteoporosis $>70$ years of age at high risk of fracture urgently require treatment for fracture prevention. Moreover, persistence with osteoporosis therapy is critical for real-world effectiveness. We estimated persistence with

Supplementary Information The online version contains supplementary material available at https:// doi.org/10.1007/s40744-021-00282-3.

S. Monov

Medical Center "Academy", Sofia, Bulgaria

S. Monov

Clinic of Rheumatology, Medical University, Sofia, Bulgaria

R. Nestorova

Rheumatology Centre "St. Irina", Sofia, Bulgaria

M. Velkova

ASIMP Rheumatology, Ruse, Bulgaria

M. Boyanov

University Hospital “Alexandrovska”, Sofia, Bulgaria

S. Jeleva

Medical Center "Orfey", St. Zagora, Bulgaria

R. Petkova $(\bowtie)$

Amgen Bulgaria, Sofia, Bulgaria

e-mail: rpetkova@amgen.com

T. Petranova

Clinic of Rheumatology, UMHAT "St. Ivan Rilsky",

Medical University, Sofia, Bulgaria denosumab in older women at high fracture risk in clinical practice in Bulgaria.

Methods: Eligible participants were postmenopausal women, $>70$ years of age, diagnosed with osteoporosis ( $T$-score $\leq-2.5$ ) and at high risk of fracture ( $\geq 3 \%$ for hip and $\geq 20 \%$ for major osteoporotic fracture) who received at least one denosumab injection before enrollment. Planned follow-up was 24 months. The primary endpoint was persistence to denosumab at 12, 18, and 24 months (defined as receiving all denosumab injections within 6 months \pm 60 days of the previous injection).

Results: 250 women were enrolled across 12 Bulgarian endocrinology/rheumatology practices; median follow up, 736 days. Mean (SD) age was 75.8 (4.2) years; mean (SD) FRAX ${ }^{\circledR}$ was 13.1 (8.6) for hip and 26.1 (9.5) for major osteoporotic fracture; 47 (18.8\%) women had prior osteoporosis therapy and 104 (41.6\%) had prior fracture. Denosumab persistence was high: $98.0 \%, 92.4 \%$, and $84.4 \%$ at 12,18 , and 24 months, respectively. A total of $42(16.8 \%)$ women discontinued denosumab during follow-up, mostly for financial reasons [25/42 $(59.5 \%)]$ or loss to follow-up [8/42 (19.0\%)]. After 24 months of denosumab treatment, BMD $T$-score improvement to the range of osteopenia $(-2.5 \leq T<-1.5)$ was achieved by $42.4 \%$ at the femoral neck, $23.6 \%$ at the lumbar spine, and $49.2 \%$ at the total hip; complete recovery ( $T$-score $\geq-1.5$ ) was observed in $9.0 \%, 26.4 \%$, 
and $23.0 \%$ respectively. New fracture was reported in 5 patients (2\%).

Conclusions: Even in an elderly population, persistence with denosumab was high despite the challenge imposed by the $50 \%$ co-pay in Bulgaria.

Trial Registration: Bulgarian Drug Agency, №НИП-0009 (registered 28.06.2017); Central Ethics Commission: NКИ-41 (registered 16.05.2017)

Keywords: Denosumab; Fracture; Medication persistence; Osteoporosis; Rank ligand inhibitor

\section{Key Summary Points}

\section{Why carry out this study?}

Taking osteoporosis medication on time and staying on medication (known as persistence) is known to be critical for reducing the risk of future fractures.

We wanted to estimate how many women $>70$ years old at high risk of fracture and treated in Bulgarian clinical practice take their six-monthly denosumab injections on time over a 2 -year period (as defined by receiving every injection within 6 months [ \pm 60 days]).

\section{What was learned from the study?}

Even in an elderly Bulgarian population, most $(98-84,8 \%)$ women at high fracture risk were persistent with their denosumab injections for up to 2 years and experienced improved bone mineral density, which is a measure of improved bone strength.

The most common reason for not receiving denosumab injections on time was financial difficulty. In Bulgaria, patients must pay $50 \%$ of the cost of osteoporosis medication out of pocket, which elderly patients may find particularly difficult due to a fixed income.

\section{DIGITAL FEATURES}

This article is published with digital features, including a summary slide and slide deck, to facilitate understanding of the article. To view digital features for this article go to https://doi. org/10.6084/m9.figshare.13280570.

\section{INTRODUCTION}

Osteoporosis is a well-characterized public health problem that is growing with the aging population in Europe [1]. In a Bulgarian epidemiological study, the prevalence of osteoporosis at the femoral neck in a sample of 1331 women aged $>50$ years was $16.8 \%$, while $46.5 \%$ had osteopenia [2]. The mean (SD) 10 -year absolute fracture risk in this sample was $13.4 \%(9.2 \%)$ for major fractures and $2.8 \%$ (5.2\%) for hip fractures. Based on these data, it was estimated that 21,476 incident fractures occurred in 1.6 million Bulgarian women who were $>50$ years old in 2010 [3].

Osteoporosis remains substantially underdiagnosed and undertreated in Bulgaria. The treatment gap for women at high risk of fracture has been estimated at 95\% in Bulgaria [3]. This is the largest treatment gap reported for any European country [1] and may be due to low reimbursement (25\% before 2016) [3] and low public healthcare spending as a proportion of gross domestic product (4.52\%). A recent crosssectional study of community-dwelling women aged $>70$ years, conducted across eight European countries, reported that three-quarters (75\%) of women at high fracture risk did not receive OP treatment, ranging from $53 \%$ in Ireland to $91 \%$ in Germany (Bulgaria was not included) [4]. In the US, only $28 \%$ of patients aged 50 and older who were hospitalized for hip fracture received a prescription to treat osteoporosis in the 12 months after discharge [5]. Hip fracture rates in the US, which had been declining from 2007 to 2013, have been increasing from 2014 to 2017 [6]. While the reasons for this change in trend are not fully understood, the severe treatment gap in osteoporosis may be part of the explanation. 
Many osteoporosis treatments are available, including oral bisphosphonates. While oral bisphosphonates are favored for their low cost, they are plagued by low medication adherence. Denosumab, a RANKL inhibitor administered once every 6 months by subcutaneous injection, provides superior fracture risk reduction compared to placebo [7] and superior gains in bone mineral density (BMD) versus oral bisphosphonates $[8,9]$. Denosumab is also associated with high medication persistence [10] and cost-effectiveness [11]. In September 2011, denosumab became commercially available in Bulgaria as a treatment of osteoporosis in postmenopausal women at increased risk of fractures [12]. In Bulgaria, patients must pay $50 \%$ of the cost of their osteoporosis medication out of pocket.

Observational studies of patients in clinical practice have shown that treatment persistence is critical for real-world effectiveness, including fracture risk reduction and BMD gains [13-17]. For example, among 35,537 women aged $\geq 45$ years, those who persisted (defined as a refill gap of $\leq 30$ days) with bisphosphonates for 24 months had $23-45 \%$ lower risk of fractures than those who did not persist [15]. In a retrospective study across several European countries, 12- and 24-month persistence with denosumab was high, ranging from 87 to $95 \%$ and 75 to $86 \%$, respectively $[18,19]$. In Bulgaria, an observational study of postmenopausal women aged $>50$ years (mean age, 63 years) reported higher persistence to denosumab at 24 months compared with monthly ibandronate ( 95.5 vs. $43.8 \%$, respectively) [20]. To date, there are no data from Bulgaria that characterize persistence with denosumab in an older population ( $>70$ years) at high fracture risk. This population is at the highest risk of fracture, especially hip fracture, which is associated with significant morbidity and mortality. While fracture risk can be assessed using the online Fracture Risk Assessment Tool (FRAX ${ }^{\circledR}$ ) [21], BMD is a good independent predictor of risk. In recent years, patients at high risk of fracture have become a focus for healthcare professionals, government agencies, and payers alike, owing to the urgency for treatment in this population.
This observational study was designed to estimate persistence with denosumab at 12,18 , and 24 months in post-menopausal women with osteoporosis, aged $>70$ years and at high risk of fracture, in real-world clinical practice in Bulgaria. Secondary objectives included patient characteristics, denosumab medicine-taking behavior, and changes in BMD.

\section{METHODS}

\section{Study Design}

This was a multicenter, retrospective/prospective, observational study conducted at 12 sites in Bulgaria. Planned follow-up was 24 months, though data were collected beyond this point where available. The study was approved by both the Bulgarian Regulatory Agency and the Bulgarian Central Ethics Commission. The study was performed in accordance with the Declaration of Helsinki and all subjects provided written informed consent.

\section{Participants}

Eligible participants were women $>70$ years of age who had been referred to endocrinologists or rheumatologists for osteoporosis diagnosis as required in Bulgaria. Participants must have been diagnosed with osteoporosis by dual X-ray absorptiometry scan ( $T$-score at the lumbar spine, femoral neck or total hip $\leq-2.5$ ), and had received at least one injection of denosumab prior to the approval of the protocol by the Bulgarian Regulatory Agency and Bulgarian Central Ethics Commission. The latter requirement was to avoid the perception that the trial was designed to induce prescription of denosumab. Fracture risk was computed using the FRAX ${ }^{\circledR}$ online tool (UK version) and the earliest values at or prior to first denosumab injection. Participants must have met FRAX $^{\circledR}$ criteria for high fracture risk (either $\geq 3 \%$ risk for hip fracture or $\geq 20 \%$ for major osteoporotic fracture). Women who had participated in clinical or medical device trials in the last 6 months or who were receiving current osteoporosis therapy were excluded from the study. 
Vitamin D and calcium supplementation were permitted. All participants provided written informed consent before being enrolled in the study.

\section{Site Selection and Data Collection}

Endocrinology or rheumatology sites were selected based on the interest in participation and the ability to enroll at least ten patients. Geographic distribution of sites, and balance between academic and private practice settings, were also considered. Sites were to enroll sequential patients.

Eligibility for enrollment and baseline data including demographics and first denosumab injection were collected retrospectively from medical records over a period of up to 6 months. Patients were considered enrolled in the prospective part of the study when they had signed the informed consent. Data were collected electronically from patient medical records. Outcomes data were collected prospectively for 24 months from the date of first denosumab injection; measurements after 24 months, where available, were also collected.

\section{Outcomes}

The primary outcome consisted of two elements: (1) persistence with denosumab, defined as no more than 60 days between scheduled injections at 12, 18, and 24 months: and (2) time to non-persistence (discontinuation) at 12 , 18 , and 24 months, defined as the total number of days between the first denosumab injection and the date a patient became non-persistent. Patients who discontinued the study were considered non-persistent.

Secondary outcomes included baseline demographics and disease characteristics; number of denosumab injections received during follow-up; change in BMD $T$-score and raw $T$-score over time; osteopenia $(-2.5 \leq T<-$ $1.5)$ or complete recovery [ $T$-score $\geq-1.5$ ] at the femoral neck, lumbar spine, and total hip; BMD changes from baseline at the femoral neck, lumbar spine, and total hip of $\leq 0 \%,>0$ to $\leq 3 \%,>3 \% \quad$ to $\leq 6 \%$ and $>6 \%$ after
24 months; fractures and adverse drug reactions (ADRs; safety events observed by the investigator or reported by the patient that occurred during follow-up).

\section{BMD}

BMD measurements and $T$-score calculations were performed per standard clinical practice in Bulgaria (i.e., once a year using the same densitometer). Baseline $\mathrm{BMD}$ and $T$-score values were defined as the most recent BMD score within the 6 months prior to the first denosumab injection; measurements at 12 months were recorded as the last measurement between baseline and 12 months; measurements at 24 months were the last measurement between 12 and 24 months; measurements after 24 months were the last recorded (although the planned follow-up was 24 months, data were collected beyond this point).

\section{Statistical Considerations}

A sample size of 250 was determined to provide acceptable precision for the 95\% confidence interval around the point estimate for persistence considering the worst-case scenario where the point estimate is $50 \%(43.8 \%, 56.2 \%)$. All available data collected during follow-up were included in the analysis with no imputation for missing data. Demographic and clinical characteristics were summarized descriptively.

The proportion of patients (95\% CI) who were persistent with denosumab at 12,18 , and 24 months (defined as no more than a 60-day gap between injections) was estimated using Kaplan-Meier methodology. The number of days a patient had been persistent to denosumab treatment was estimated with discontinuation considered as a failure event. Sensitivity analyses for the primary outcome included persistence estimates for 30-day and 90-day gaps between injections. Post hoc statistical comparisons of gap length were performed using the Chi-squared test (Suppl Table S1). All statistical analyses and graphs were performed using the $\mathrm{R}$ statistical package in version 3.6.2. 


\section{RESULTS}

\section{Disposition}

The first patient was enrolled in July 2017 and the last patient completed the study in November 2019. A total of 250 eligible women were enrolled in the study and 212 (84.4\%) completed the follow-up period of 24 months. Of the $38(15.2 \%)$ patients who discontinued the study, 17 (44.7\%) withdrew consent, eight (21.1\%) were lost to follow-up, two (5.3\%) died, one $(2.6 \%)$ withdrew by decision of the investigator, one $(2.6 \%)$ had an adverse event unrelated to denosumab, and nine (23.7\%) withdrew for the reason "other". During followup, $42(16.8 \%)$ patients discontinued denosumab; the most common reasons for discontinuing denosumab were financial reasons in 25 patients $(59.5 \%)$ and loss to follow-up in eight patients (19\%). Average follow-up, covering the time span defined in the protocol (up to the 24th month), took 710.7 days $(S D=62.1)$, with median $=730$ days $(363-730)$.

\section{Patients}

Patient characteristics are shown in Table 1. Median age (Q1, Q3) was $75(72,79)$ years; 51 (20.4\%) patients were over 80 years of age. A prior fracture was documented in 104 patients (41.6\%). The 10-year probability of fracture risk by FRAX $^{\circledR}$ for major osteoporotic fracture ranged from 8.5 to $65 \%$ with a median $(\mathrm{Q} 1, \mathrm{Q} 3)$ of $25 \%(19,31)$. For hip fracture, the probability ranged from 3 to $56 \%$, with a median (Q1, Q3) of $11 \%(7,17)$. A total of 47 patients had received prior osteoporosis therapy, mainly bisphosphonates $(80.9 \%)$; where recorded, the major reason for discontinuing bisphosphates was lack of effect.

\section{Persistence}

For the primary endpoint, persistence with denosumab (all refills within 6 months \pm 60 days) was high at 12,18 , and 24 months: $98.0,92.4$, and $84.4 \%$, respectively (Fig. 1). Figure 2 shows the Kaplan-Meier estimated persistence over time. Median time to non-persistence at 12,18 , and 24 months could not be estimated as the probability did not cross $50 \%$; however, we can conclude that the median persistence time was likely to be at least 24 months. The main reasons for non-persistence were medication discontinuation and treatment delay (Table 2). Of the 19 patients who discontinued denosumab, 13 (68.4\%) reported that the reason was financial. Sensitivity analyses showed notably lower persistence when a refill gap of 30 days was used, and similar persistence when a 90-day gap was used (Table S1).

\section{Medication Usage}

Most patients (82.8\%) received all five scheduled denosumab injections during the study. The median number of injections was 5 (range, $1-5)$.

\section{BMD}

At baseline, median BMD $T$-scores were -2.7 at the femoral neck, -2.9 at the lumbar spine, and - 2.6 at the total hip; after 24 months these were $-2.5,-2.5$, and -2.2 , respectively (Fig. 3a). BMD $T$-score s increased at each of the locations over time, with participants achieving a median increase of 0.3 at the femoral neck and total hip, and 0.7 at the lumbar spine after 24 months (Fig. 3b). The percentage of patients achieving osteopenia $(-2.5 \leq T<-1.5)$ and complete recovery ( $T$-score $\geq 1.5$ ) at 12 and 24 months are shown in Fig. 4. After 24 months, $42.4,23.6$, and $49.2 \%$ of patients achieved osteopenia at the femoral neck, lumbar spine, and total hip, respectively. Complete recovery was achieved by $9.0 \%$ of patients at the femoral neck, $26.4 \%$ at the lumbar spine, and $23 \%$ at the total hip. Evaluating BMD T-score change by the increase achieved, $64 \%$ of patients achieved $>6 \%$ increase at any location; $12 \%$ achieved an improvement between 3 and $6 \%$; $1 \%$ achieved $0-3 \%$; and $23 \%$ achieved $\leq 0 \%$ improvement. 
Table 1 Baseline demographic and clinical characteristics

\begin{tabular}{|c|c|}
\hline & Patients $(N=250)$ \\
\hline Age, years, median (Q1, Q3) & $75(72,79)$ \\
\hline Age at menopause, years, median (Q1, Q3) & $50(46,50)$ \\
\hline \multicolumn{2}{|l|}{ Fracture risk factors, $n(\%)$} \\
\hline History of fracture & $104(41.6 \%)$ \\
\hline Parent fractured hip & $72(28.8 \%)$ \\
\hline Current smoking & $20(8.0 \%)$ \\
\hline Systemic glucocorticoid use & $30(12.0 \%)$ \\
\hline Rheumatoid arthritis & $22(8.8 \%)$ \\
\hline Secondary osteoporosis & $33(13.2 \%)$ \\
\hline$\geq 3$ units of alcohol per day & $0(0 \%)$ \\
\hline \multicolumn{2}{|l|}{ FRAX $^{\circledR}$ 10-year probability, median (Q1, Q3) } \\
\hline Major osteoporotic fracture & $25 \%(19,31)$ \\
\hline Hip fracture & $11 \%(7,17)$ \\
\hline Previous osteoporosis therapy, $n$ (\%) & $47(18.8 \%)$ \\
\hline Bisphosphonates, $n$ (\% of 47 ) & $38(80.9 \%)$ \\
\hline \multicolumn{2}{|c|}{ Main reason for discontinuing prior osteoporosis therapy in those with history of discontinuation, $n=20, n$ (\% of 20 ) } \\
\hline Lack of effect & $12(60.0 \%)$ \\
\hline Financial reason & $3(15.0 \%)$ \\
\hline Adverse events & $3(15.0 \%)$ \\
\hline Calcium supplementation, $n(\%)$ & $160(64.0 \%)$ \\
\hline Vitamin D supplementation, $n(\%)$ & $207(82.8 \%)$ \\
\hline \multicolumn{2}{|l|}{ Most common comorbidities, $n$ (\%) } \\
\hline Cardiovascular & $158(51 \%)$ \\
\hline Musculoskeletal & $36(11.6 \%)$ \\
\hline Metabolic & $30(9.7 \%)$ \\
\hline Central nervous system & $24(7.7 \%)$ \\
\hline
\end{tabular}

FRAX® Fracture Risk Assessment Tool

\section{Fractures}

A total of six fractures were reported in five patients (2\%): two radius fractures and one each of hip ( $0.4 \%$ hip fracture rate), vertebral, elbow, and pubis fracture. One patient experienced two fractures at the same time (radius and elbow). Four fractures in four patients required hospitalization and three fractures in three patients required surgical intervention. 


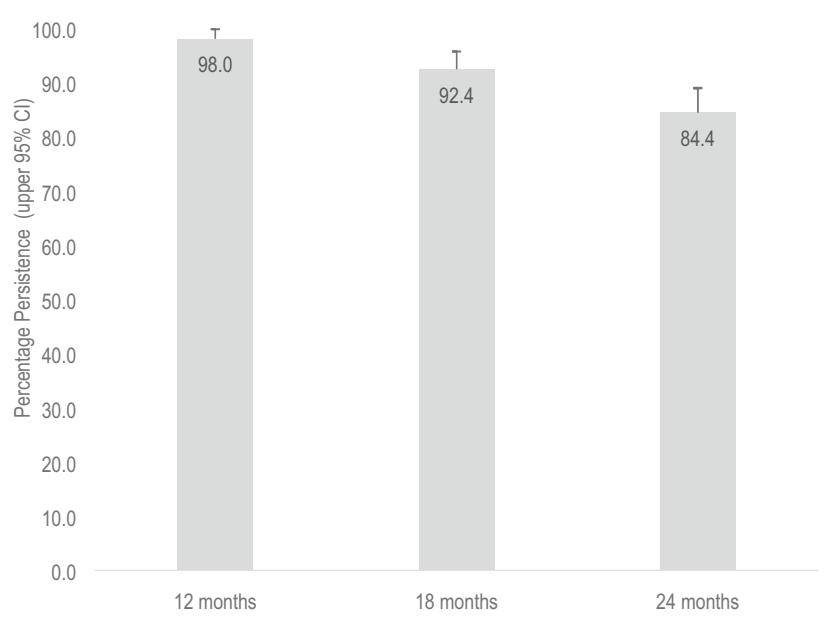

Fig. 1 Kaplan-Meier estimated probability with upper 95\% CI of persistence with denosumab at 12, 18, and 24 months for medication refill gaps of 60 days (primary endpoint)

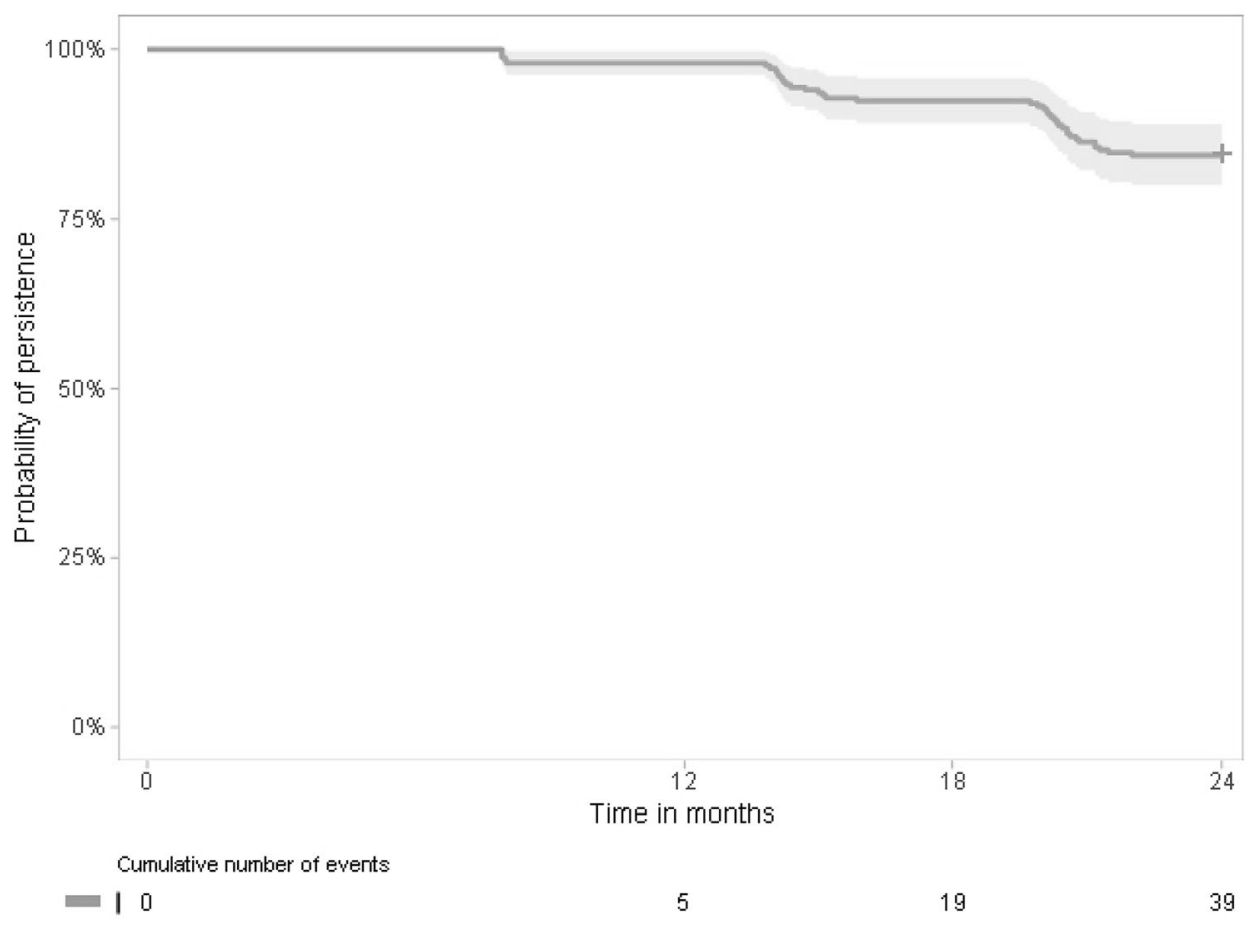

Fig. 2 Kaplan-Meier estimated probability with $95 \%$ CI of persistence with denosumab over 24 months for medication refill gaps of 60 days

\section{Adverse Drug Reactions}

Four adverse drug reactions were reported in two patients at any time following the first injection of denosumab, none of which was considered related to denosumab: breast cancer, pancreatic cancer, ischemic stroke, and cardiopulmonary failure; both patients died. 
Table 2 Reasons for non-persistence

\begin{tabular}{llcr}
\hline Reason, $\boldsymbol{n}(\%)$ & \multicolumn{2}{l}{ Patients $(\boldsymbol{N}=\mathbf{2 5 0})$} & $\mathbf{2 4}$ months \\
\cline { 2 - 4 } & $\mathbf{1 2}$ months & $\mathbf{1 8}$ months & $7(2.8 \%)$ \\
\hline Lost to follow-up & $1(0.4 \%)$ & $3(1.2 \%)$ & $2(0.8 \%)$ \\
Death & $0(0 \%)$ & $1(0.4 \%)$ & $19(7.6 \%)$ \\
Medication discontinuation $^{\mathrm{a}}$ & $1(0.4 \%)$ & $7(2.8 \%)$ & $11(4.4 \%)$ \\
Dose delay $_{\text {Total }}$ & $3(1.2 \%)$ & $8(3.2 \%)$ & $39(15.6 \%)$ \\
\hline
\end{tabular}

a After medication discontinuation, patients were discontinued from the study and were no longer followed

\section{Calcium and Vitamin D Supplementation}

At baseline, $64 \%$ of patients were receiving calcium and $83 \%$ patients were receiving vitamin D. Calcium and vitamin D supplementation improved after the first denosumab injection, with $82-74 \%$ receiving calcium and $99-100 \%$ of patients receiving vitamin $\mathrm{D}$ supplementation over the course of the study. Calcium and vitamin D supplements are paid out of pocket by the patients in Bulgaria.

\section{DISCUSSION}

In this prospective observational cohort study of 250 Bulgarian women over 70 years of age at high risk of fracture, persistence with denosumab injections was high $(98 \%$ at 12 months and $84 \%$ at 24 months). The main reasons for non-persistence were discontinuation (mostly due to financial reasons) and a longer gap between medication refills than allowed (i.e., $>60$ days). The median age of our cohort was 75 years with 51 (20\%) women over 80 years of age; $41.6 \%$ of patients had a prior fracture, and the median FRAX $^{\circledR}$ risk was $25 \%$ for major osteoporotic fracture and $11 \%$ for hip fracture. After 24 months of denosumab treatment, BMD $T$-scores at the femoral neck, lumbar spine, and total hip had improved to the range of osteopenia $(-2.5 \leq T<-1.5)$ in $42.4 \%, 23.6 \%$ and $49.2 \%$ of patients respectively, while complete recovery ( $T$-score $\geq-$ 1.5) was observed in $9.0,26.4$, and $23.0 \%$ of patients, respectively. The majority of patients (64\%) achieved $>6 \%$ increase in BMD at any location during the study. Two percent of patients experienced a fracture during the study. These results show generally high persistence with denosumab accompanied by BMD $T$-score gains in a population of Bulgarian women at high risk of fracture.

Denosumab persistence observed in this older high-risk population was better or comparable to that reported in other European cohorts $[18,19,22,23]$ and substantially higher than that reported in North America [24, 25]. However, compared with a prior study in a younger cohort of Bulgarian women [20], we observed lower 24-month denosumab persistence ( 84 vs. $99 \%)$, possibly indicating that the older group of patients enrolled in our study may have experienced greater challenges in remaining on treatment. In our study, the main reason for discontinuing denosumab was financial (59.5\%), whereas only $20 \%$ of discontinuations in the younger population [20] were attributed to financial reasons. Thus, it appears that this group of retired women on a pension faced more difficulty in affording the 50\% copayment required for osteoporosis medications in Bulgaria.

A 60-day permissible gap is typically used when defining persistence to osteoporosis medication [18, 19, 24]. In sensitivity analyses, we found that a 30-day gap notably reduced persistence, whereas there was little difference between 60- and 90-day gaps. Thus, while fewer patients managed to refill denosumab within 

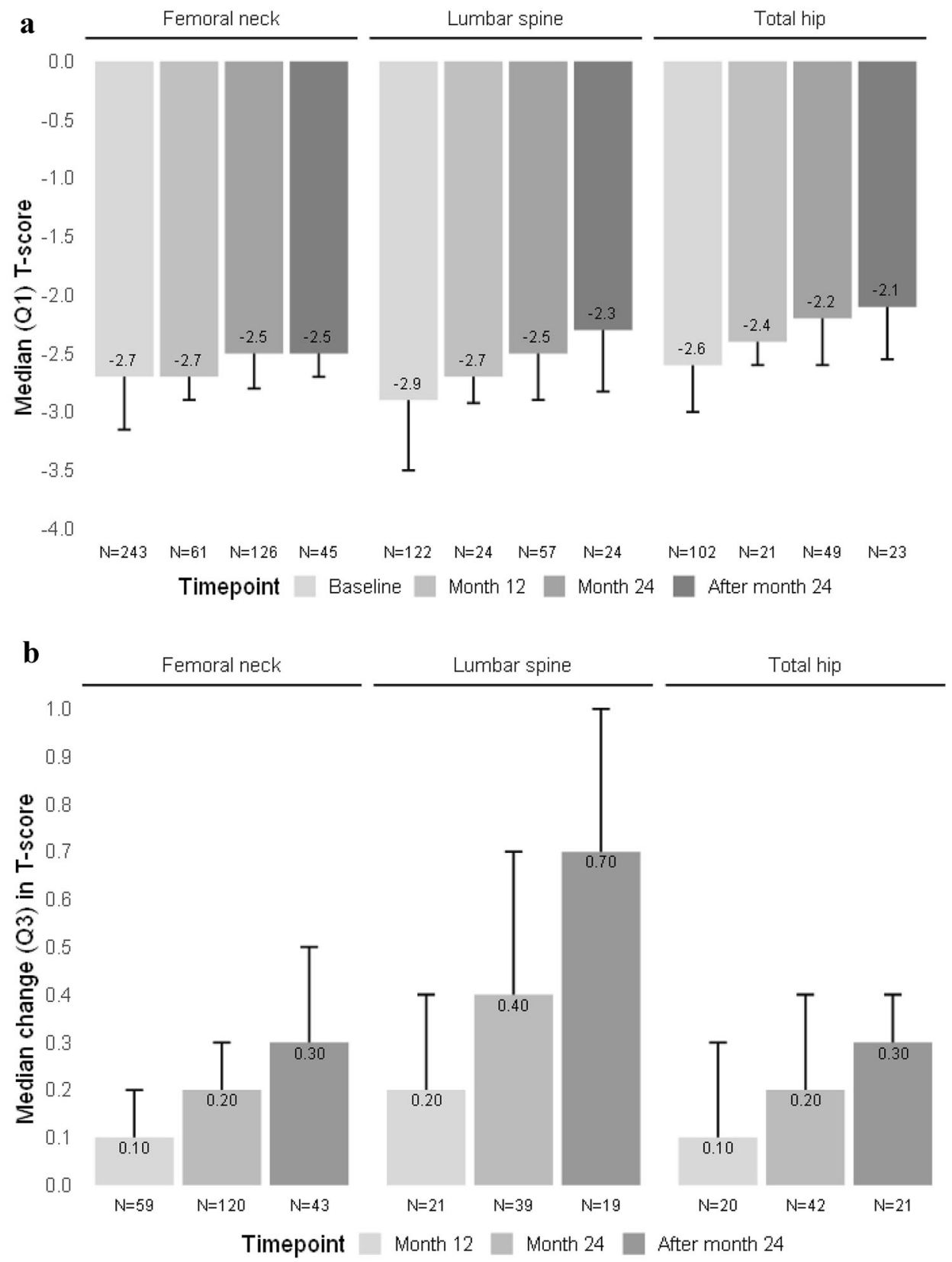

Fig. 3 BMD $T$-score over time. a $T$-score and $\mathbf{b}$ median change from baseline $T$-score

30 days, most achieved refill within 60 days. A recent observational study in 2594 patients in the UK showed that delays of less than 4 months in receiving denosumab were not associated with increased fracture risk, while delays of greater than 4 months increased fracture risk [26]. With bisphosphonates however, much shorter gaps had an impact on fracture risk: in a claims-based study of 35,537 patients, those who achieved refills of bisphosphonate within 30 days had $23-45 \%$ lower fracture risk [15]. The difference in acceptable refill gap times is likely due to the shorter half-life of bisphosphonates relative to denosumab.

In Bulgaria, the process of prescribing osteoporosis treatment is complicated by 


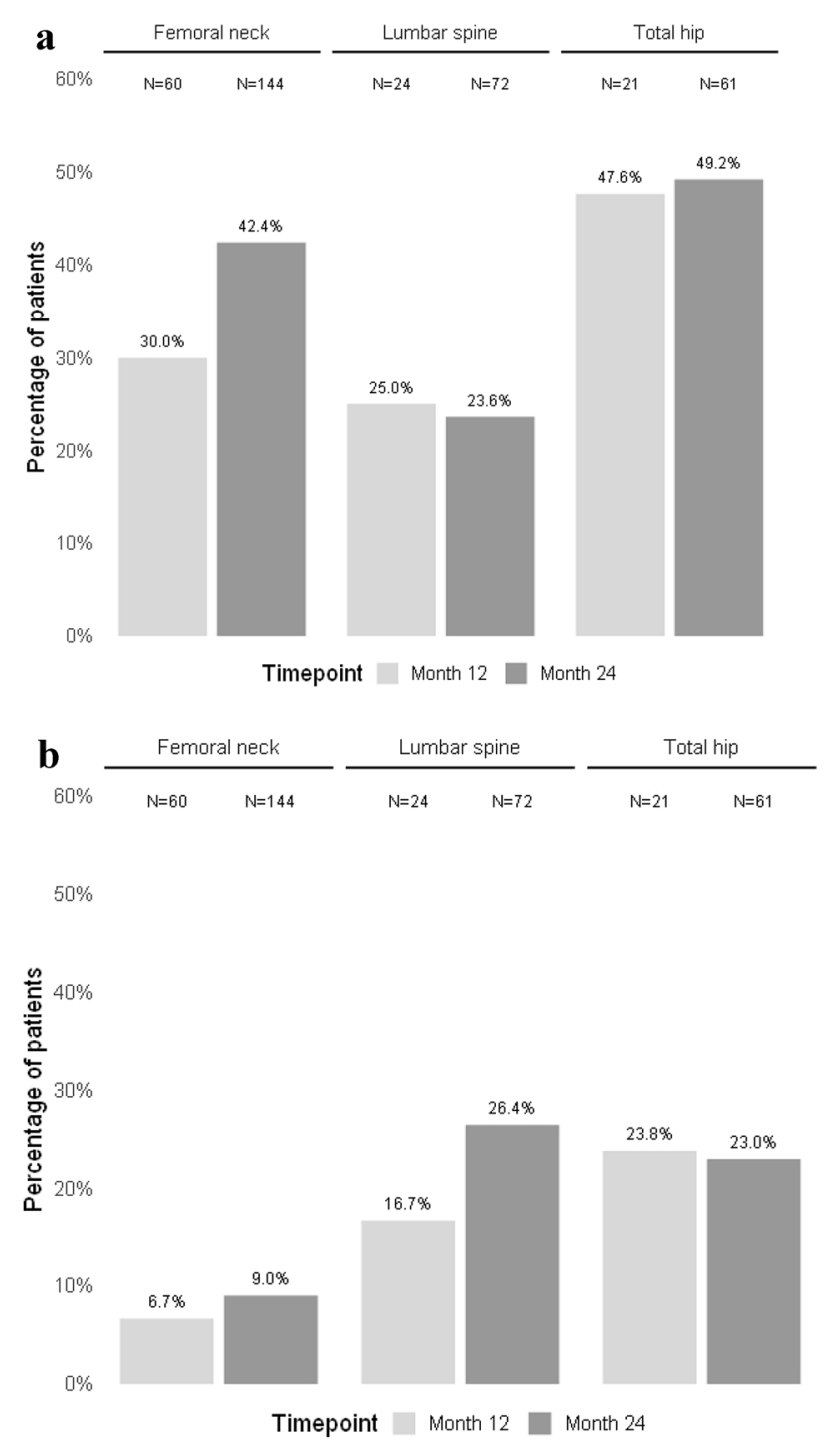

Fig. 4 Percentage of patients achieving osteopenia or recovery. a Osteopenia $(T$ score $\leq-2.5$ to $>-1.5)$ and $\mathbf{b}$ recovery $(T$ score $\leq-1.5)$

reimbursement rules which require that specialists diagnose osteoporosis but allow only the general practitioner to complete the reimbursement fund prescription. This burdensome procedure requires patients to navigate a long process and likely contributes to longer gap times. Along with the 50\% co-payment, elderly patients in Bulgaria therefore face a challenging path for adhering and persisting with osteoporosis treatment.

BMD is a known independent predictor of fracture risk, with BMD $T$-score $\mathrm{s}$ of $\geq-2.5$ associated with lower risk [27]. At baseline, median BMD $T$-score $s$ in our study were -2.7 at the femoral neck, -2.9 at the lumbar spine, and -2.6 at the total hip; at 24 months, median scores were $-2.5,-2.5$, and -2.2 , respectively. By comparison, in the younger Bulgarian cohort noted above, median scores at baseline were 3.2 at the lumbar spine and -2.6 at the femoral neck, followed by -2.7 and -2.4 respectively at 24 months [20]. Therefore, the BMD $T$-score changes were similar in these two studies. Of note, recent clinical trial analyses suggest that fracture risk continues to diminish at lower $T$ score thresholds: evidence from the FREEDOM 
and $\mathrm{ARCH}$ trials suggest that a patient will remain at high fracture risk of future fracture until a total hip BMD $T$-score of -1.5 is reached $[28,29]$. Treat-to-target strategies that include $T$-score -1.5 are now under discussion [30]. In the present study, complete recovery ( $T$-score $\geq$ - 1.5) was achieved by $9.0 \%$ of patients at the femoral neck, $26.4 \%$ at the lumbar spine and $23.0 \%$ at the total hip.

We observed a fracture rate of $2 \%$ and a hip fracture rate of $0.4 \%$ over 24 -months follow-up in our high-risk cohort of denosumab users, comparable to that observed in the younger cohort study in Bulgaria $(1.3 \%$ and $0.45 \%$, respectively) [20]. These rates are low and comparable to the annual fracture rates observed in the 10-year data from the FREEDOM trial [31].

There are several limitations to this study. Our results may not be generalizable to other countries due to difference in patient populations and clinical practice. Based on reimbursement rules in Bulgaria, participants in our study were diagnosed by specialists and therefore may not be comparable to patients diagnosed by non-specialists in other countries. Patients were only eligible to receive denosumab in Bulgaria at a $T$-score of $\leq-2.5$, therefore we could not include patients with baseline $T$-scores $>-2.5$, despite the fact that such patients might have been at high fracture risk after a fragility fracture and might have been treated in other countries. Additionally, the participants may have been motivated to persist based on their participation in the study and therefore the rate of persistence may have been overestimated.

\section{CONCLUSIONS}

In this prospective observational study of patients with osteoporosis at high risk of fracture, we observed a high rate of persistence to denosumab in Bulgarian clinical practice, with $84 \%$ of patients remaining on treatment at 24 months. Improvements in BMD T-score at all locations along with a notable proportion of patients achieving osteopenia or recovery suggest that denosumab is effective in treating patients at high risk of fracture in clinical practice.

\section{ACKNOWLEDGEMENTS}

We are grateful to the study participants for their involvement in this research.

Funding. This study was sponsored by Amgen (Europe) GmbH. The sponsor supported the Rapid Service Fee for the article.

Editorial Assistance. Wanda J Krall, $\mathrm{PhD}$ of Wanda Krall Medial Communications, Switzerland, provided editorial assistance funded by Amgen.

Authorship. All named authors meet the International Committee of Medical Journal Editors criteria for authorship for this article, take responsibility for the integrity of the work as a whole, and have given their approval for this version to be published.

Disclosures. Simeon Monov has received consulting fees from Novartis, Pfizer, AbbVie, MSD, and Eli Lilly; and speaker's bureau fees from Amgen, Pfizer, AbbVie, and MSD; Rodina Nestorova has received consulting fees from Amgen, AbbVie, Novartis, Sandoz, Roche, Pfizer, Janssen, and UCB; speaker's bureau fees from Amgen, AbbVie, Novartis, Roche, and Pfizer; Margarita Velkova has received research grants from Amgen, consulting fees from Amgen, Novartis, and AbbVie; and speaker's bureau fees from AbbVie and Sandoz; Mihail Boyanov has received speaker's bureau fees for Amgen, Astra Zeneca, Servier, NovoNordisk, EGIS, Merck, and Eli Lilly; Silvia Jeleva has received consulting fees from Roche, AbbVie, Novartis, and Amgen; Renata Petkova is employed by Amgen and holds Amgen stock; Tzvetanka Petranova has received speaker fees from MSD, Novartis, Roche, Amgen, Elly Lilly, Pfizer and honoraria for advisory board meetings from Amgen and Elly Lilly.

Compliance with Ethics Guidelines. The study was approved by both the Bulgarian 
Regulatory Agency and the Bulgarian Central Ethics Commission. The study was performed in accordance with the Declaration of Helsinki and all subjects provided written informed consent.

Data Availability. Qualified researchers may request data from Amgen clinical studies. Complete details are available at the following: https://wwwext.amgen.com/science/clinicaltrials/clinical-data-transparencypractices/.

Open Access. This article is licensed under a Creative Commons Attribution-NonCommercial 4.0 International License, which permits any non-commercial use, sharing, adaptation, distribution and reproduction in any medium or format, as long as you give appropriate credit to the original author(s) and the source, provide a link to the Creative Commons licence, and indicate if changes were made. The images or other third party material in this article are included in the article's Creative Commons licence, unless indicated otherwise in a credit line to the material. If material is not included in the article's Creative Commons licence and your intended use is not permitted by statutory regulation or exceeds the permitted use, you will need to obtain permission directly from the copyright holder. To view a copy of this licence, visit http://creativecommons.org/licenses/by$\mathrm{nc} / 4.0 /$.

\section{REFERENCES}

1. Hernlund E, Svedbom A, Ivergard M, Compston J, Cooper C, Stenmark J, et al. Osteoporosis in the European Union: medical management, epidemiology and economic burden. A report prepared in collaboration with the International Osteoporosis Foundation (IOF) and the European Federation of Pharmaceutical Industry Associations (EFPIA). Arch Osteoporos. 2013;8:136.

2. Borissova AM, Rashkov R, Boyanov M, Shinkov A, Popivanov $\mathrm{P}$, Temelkova $\mathrm{N}$, et al. Femoral neck bone mineral density and 10-year absolute fracture risk in a national representative sample of Bulgarian women aged 50 years and older. Arch Osteoporos. 2011;6:189-95.
3. Svedbom A, Hernlund $\mathrm{E}$, Ivergård $\mathrm{M}$, Compston J, Cooper C, Stenmark J, et al. Epidemiology and economic burden of osteoporosis in Bulgaria. Arch Osteoporos. 2013;8:137.

4. McCloskey E, Rathi J, Heijmans S, Blagden M, Cortet B, Czerwinski E, et al. The osteoporosis treatment gap in patients at risk of fracture in European primary care: a multi-country cross-sectional observational study. Osteoporos Int. 2020;32(2):1-9.

5. Solomon DH, Johnston SS, Boytsov NN, McMorrow D, Lane JM, Krohn KD. Osteoporosis medication use after hip fracture in US patients between 2002 and 2011. J Bone Miner Res. 2014;29(9):1929-37.

6. Lewiecki EM, Chastek B, Sundquist K, Williams SA, Weiss RJ, Wang Y, et al. Osteoporotic fracture trends in a population of US managed care enrollees from 2007 to 2017. Osteoporos Int. 2020;31(7): 1299-304.

7. Cummings SR, San Martin J, McClung MR, Siris ES, Eastell R, Reid IR, et al. Denosumab for prevention of fractures in postmenopausal women with osteoporosis. N Engl J Med. 2009;361(8):756-65.

8. Brown JP, Prince RL, Deal C, Recker RR, Kiel DP, de Gregorio LH, et al. Comparison of the effect of denosumab and alendronate on BMD and biochemical markers of bone turnover in postmenopausal women with low bone mass: a randomized, blinded, phase 3 trial. J Bone Miner Res. 2009;24(1):153-61.

9. Kendler DL, Roux C, Benhamou CL, Brown JP, Lillestol M, Siddhanti S, et al. Effects of denosumab on bone mineral density and bone turnover in postmenopausal women transitioning from alendronate therapy. J Bone Miner Res. 2010;25(1): 72-81.

10. Jonsson E, Cheng LI, Strom O, Intorcia M, Karlsson L. Systematic review and meta-analysis of persistence with denosumab in patients with osteoporosis. Value Health. 2014;17(7):A383-4.

11. Morizio P, Burkhart JI, Ozawa S. Denosumab: a unique perspective on adherence and cost-effectiveness compared with oral bisphosphonates in osteoporosis patients. Ann Pharmacother. 2018;52(10):1031-41.

12. https://portal.ncpr.bg/registers/pages/register/listmedicament.xhtml. Accessed 25 May 2020.

13. Betella N, Biamonte E, Matarazzo C, Piccini S, Olivetti $R$, Cellini $M$, et al. Suboptimal medication adherence may favor the progression of vertebral fractures in women with post-menopausal osteoporosis under treatment with denosumab: a real-life 
observational study. Minerva Endocrinol. 2020;45(3):165-71.

14. Patrick AR, Brookhart MA, Losina E, Schousboe JT, Cadarette SM, Mogun H, et al. The complex relation between bisphosphonate adherence and fracture reduction. J Clin Endocrinol Metab. 2010;95(7):3251-9.

15. Siris ES, Harris ST, Rosen CJ, Barr CE, Arvesen JN, Abbott TA, et al. Adherence to bisphosphonate therapy and fracture rates in osteoporotic women: relationship to vertebral and nonvertebral fractures from 2 US claims databases. Mayo Clin Proc. 2006;81(8):1013-22.

16. Landfeldt E, Strom O, Robbins S, Borgstrom F. Adherence to treatment of primary osteoporosis and its association to fractures-the Swedish Adherence Register Analysis (SARA). Osteoporos Int. 2012;23(2):433-43.

17. Hadji P, Claus V, Ziller V, Intorcia M, Kostev K, Steinle T. GRAND: the German retrospective cohort analysis on compliance and persistence and the associated risk of fractures in osteoporotic women treated with oral bisphosphonates. Osteoporos Int. 2012;23(1):223-31.

18. Hadji P, Papaioannou N, Gielen E, Feudjo Tepie M, Zhang E, Frieling I, et al. Persistence, adherence, and medication-taking behavior in women with postmenopausal osteoporosis receiving denosumab in routine practice in Germany, Austria, Greece, and Belgium: 12-month results from a European non-interventional study. Osteoporos Int. 2015;26(10):2479-89.

19. Fahrleitner-Pammer A, Papaioannou N, Gielen E, Feudjo Tepie M, Toffis C, Frieling I, et al. Factors associated with high 24-month persistence with denosumab: results of a real-world, non-interventional study of women with postmenopausal osteoporosis in Germany, Austria, Greece, and Belgium. Arch Osteoporos. 2017;12(1):58.

20. Petranova T, Boyanov M, Shinkov A, Petkova R, Intorcia M, Psachoulia E. Medication-taking behaviour in Bulgarian women with postmenopausal osteoporosis treated with denosumab or monthly oral bisphosphonates. Arch Osteoporos. 2017;13(1): 1.

21. Kanis JA, Oden A, Johnell O, Johansson H, De Laet C, Brown J, et al. The use of clinical risk factors enhances the performance of BMD in the prediction of hip and osteoporotic fractures in men and women. Osteoporos Int. 2007;18(8):1033-46.

22. Morley J, Moayyeri A, Ali L, Taylor A, Feudjo-Tepie M, Hamilton L, et al. Persistence and compliance with osteoporosis therapies among postmenopausal women in the UK Clinical Practice Research Datalink. Osteoporos Int. 2020;31(3):533-45.

23. Reyes C, Tebe C, Martinez-Laguna D, Ali MS, SoriaCastro A, Carbonell C, et al. One and two-year persistence with different anti-osteoporosis medications: a retrospective cohort study. Osteoporos Int. 2017;28(10):2997-3004.

24. Durden E, Pinto L, Lopez-Gonzalez L, Juneau P, Barron R. Two-year persistence and compliance with osteoporosis therapies among postmenopausal women in a commercially insured population in the United States. Arch Osteoporos. 2017;12(1):22.

25. Ban JK, Hao BB, McCarthy L, Guilcher SJT, Cadarette SM. Denosumab utilization among older adults in Ontario: patient characteristics, persistence with therapy, and return to therapy after an extended gap. Osteoporos Int. 2019;30(9):1865-72.

26. Lyu H, Yoshida K, Zhao SS, Wei J, Zeng C, Tedeschi $\mathrm{SK}$, et al. Delayed denosumab injections and fracture risk among patients with osteoporosis: a population-based cohort study. Ann Intern Med. 2020;173(7):516-26.

27. Bagger YZ, Tanko LB, Alexandersen P, Hansen HB, Qin G, Christiansen C. The long-term predictive value of bone mineral density measurements for fracture risk is independent of the site of measurement and the age at diagnosis: results from the prospective epidemiological risk factors study. Osteoporos Int. 2006;17(3):471-7.

28. Ferrari S, Libanati C, Lin CJF, Brown JP, Cosman F, Czerwinski E, et al. Relationship between bone mineral density $T$-score and nonvertebral fracture risk over 10 years of denosumab treatment. J Bone Miner Res. 2019;34(6):1033-40.

29. Cosman F, Lewieck iEM, Ebeling PR, Hesse E, Napoli $\mathrm{N}$, Crittenden DB, et al. T-Score as an indicator of fracture risk on therapy: evidence from romosozumab vs alendronate treatment in the active-controlled fracture study in postmenopausal women with osteoporosis at high risk trial [abstract]. Arthritis Rheumatol. 2018;70 Suppl 10:1333-42.

30. Thomas T, Casado E, Geusens P, Lems WF, Timoshanko J, Taylor D, et al. Is a treat-to-target strategy in osteoporosis applicable in clinical practice? Consensus among a panel of European experts. Osteoporos Int. 2020;31(12):2303-11.

31. Bone HG, Wagman RB, Brandi ML, Brown JP, Chapurlat R, Cummings SR, et al. 10 years of denosumab treatment in postmenopausal women with osteoporosis: results from the phase 3 randomised FREEDOM trial and open-label extension. Lancet Diabetes Endocrinol. 2017;5(7):513-23. 